6. C. S. Meijer, "Expansion theorems for the G-functions. I-X," Indag. Math., v. 14, 1952, pp. $369-379$ and $483-487$; v. 15 , 1953, pp. 43-49, 187-193 and 349-357; v. 16, 1954, pp. 77-82, 83-91 and 273-279; v. 17, 1955, pp. 243-251 and 309-314. MR 14, 469; MR 14, 642; MR 14, 748; MR 14, 979; MR 15, 422; MR 15, 791; MR 15, 955; MR 16, 1106.

7. A. Verma, "A class of expansions of $G$-functions and the Laplace transform," Math. Comp., v. 19, 1965, pp. 661-664.

8. A. VERMA, "Expansions of hypergeometric functions of two variables", Math. Comp., v. $20,1966,590-596$.

9. A. Verma, "A note on an expansion of hypergeometric functions of two variables", Math. Comp., v. 20, 1966, 413-417.

10. J. WIMP \& Y. L. LUKe, "Expansion formulas for generalised hypergeometric functions", Rend. Circ. Mat. Palermo, (2), v. 11, 1962, pp. 351-366.

\title{
Approximations for the Psi (Digamma) Function
}

\section{By William T. Moody}

A series of approximations has been derived for the psi function. As used here, the psi function is defined as the derivative of the natural logarithm of the gamma function; that is

$$
\psi(x)=\frac{d[\ln \Gamma(x)]}{d x}=\frac{\Gamma^{\prime}(x)}{\Gamma(x)} .
$$

The approximations are best in the Chebyshev sense, in that the magnitude of the maximum error in the prescribed interval is minimized. Each approximation is of the form

wherein

$$
\psi(1+x)=\frac{x}{1+x}-\gamma+\frac{1}{2} x^{n+1}+\sum_{i=1}^{n} c_{i}\left(x^{i}-x^{n+1}\right)+\epsilon(x), \quad 0 \leqq x \leqq 1,
$$

$$
\gamma=0.5772 \cdots, \quad \text { (Euler's constant). }
$$

Values of the constants, $c_{i}$, and the limiting values of $\epsilon$ for $n=4,5,6$ are given in Table 1 below. The error of the approximation vanishes at the end points.

\begin{tabular}{|c|c|c|c|}
\hline$n \ldots \ldots$ & 4 & 5 & 6 \\
\hline$\epsilon<$ & $1.3 \times 10^{-6}$ & $1.3 \times 10^{-7}$ & $1.3 \times 10^{-8}$ \\
\hline$i$ & \multicolumn{3}{|c|}{$c_{i}$} \\
\hline $\begin{array}{l}1 \\
2 \\
3 \\
4 \\
5 \\
6\end{array}$ & $\begin{array}{c}+0.644876 \\
-0.201186 \\
+0.077968 \\
-0.026867 \\
-\end{array}$ & $\begin{array}{c}+0.6449266 \\
-0.2019040 \\
+0.0812656 \\
-0.0334532 \\
+0.0111653\end{array}$ & $\begin{array}{r}+0.64493313 \\
-0.20203181 \\
+0.08209433 \\
-0.03591665 \\
+0.01485925 \\
-0.00472050\end{array}$ \\
\hline
\end{tabular}

TABLE 1

Values of Constants

Bureau of Reclamation

Federal Center

Denver, Colorado

Received March 28, 1966. Revised August 4, 1966. 